\title{
Hyperbaric oxygen in multiple sclerosis: a double blind trial
}

\author{
C M WILES, C R A CLARKE, H P IRWIN, E F EDGAR, A V SWAN
}

\begin{abstract}
Eighty four patients with multiple sclerosis were treated in monoplace chambers with either hyperbaric oxygen at 2 atmospheres absolute or placebo. Comprehensive double blind assessment was carried out before, immediately after, and one month after treatment. There was no clinically important or significant benefit in any of the four major criteria of outcome-namely, the patient's subjective opinion, the examiner's opinion, the score on the Kurtzke disability status scale, or the time taken to walk $50 \mathrm{~m}$. Out of 40 other clinical variables assessed, two (the sensory scale and timed writing with the left hand) showed a significant improvement without any subjective clinical correlate or change in any of seven other tests of left hand function. No group of symptoms was perceived by the patients as having improved more after treatment with hyperbaric oxygen than placebo.

It is concluded that there is no basis for recommending hyperbaric oxygen in the treatment of multiple sclerosis.
\end{abstract}

\section{Introduction}

Since 1970 there have been several claims that hyperbaric oxygen might have a beneficial effect in multiple sclerosis. ${ }^{1-7}$ The theoretical basis for such improvements remains uncertain, although experimental studies in traumatic paraplegia and allergic encephalomyelitis,${ }^{89}$ and clinical studies in spinal cord injury and after head injury, ${ }^{10-12}$ have indicated a potential role in treating neurological lesions. Uncontrolled, non-blind trials yielded generally but not exclusively beneficial results. ${ }^{1-6}{ }^{13}$ One small double blind, placebo controlled study in chronic multiple sclerosis showed objective improvement in 12 of 17 patients treated with oxygen at 2

St Thomas's Hospital, London SE1 7EH

CM WILES, PHD, MRCP, consultant neurologist

H P IRWIN, SRN, research sister

A V SWAN, MSC, deputy director, health services research unit

Whipps Cross Hospital, London E11

C R A CLARKE, MD, FRCP, consultant neurologist

E F EDGAR, SRN, research sister

Correspondence to: Dr Wiles. atmospheres absolute compared with one of 20 treated with placebo. These improvements were seen at the end of treatment and most commonly affected mobility, balance, and fatigability: three patients were described as having a "marked, longlasting" response. ${ }^{7}$ Subsequently the Multiple Sclerosis Society commissioned further trials in Newcastle and London (the present study). In the Newcastle study no significant improvements were found in 60 patients treated with oxygen compared with 57 controls apart from a subjective improvement in function of the bowel and bladder. ${ }^{14}$

We report the results obtained immediately and one month after treatment with hyperbaric oxygen or placebo in 84 patients under double blind conditions. We accepted that it might be difficult to measure improvements in physical state corresponding to worthwhile symptomatic benefits, notably in walking, balance, urinary function, and fatigue. We therefore used a wide range of methods of assessment, including a detailed analysis of the patients' subjective impression of change, measures of impairment of specific functions and activities (for example, hand function, strength, quantitative sensory testing, walking time), and the standard Kurtzke scales of disability, incapacity, and functional systems. In this way we tried to reduce the likelihood of obtaining a false negative result because of inappropriate or insensitive methods of assessment.

\section{Methods \\ PATIENTS}

Patients either were already under the care of the departments of neurology at these hospitals or were referred by their general practitioners or consultants elsewhere. To be eligible they had to have clinically definite or probable progressive multiple sclerosis ${ }^{15}$ and to know the diagnosis: only patients who could walk $50 \mathrm{~m}$, whether or not with bilateral support, were considered. Relapse within the year before entry, administration of corticosteroids or immunosuppressive agents within six months before entry, pregnancy, any serious psychiatric or general medical disorder (particularly chronic obstructive airways disease), epilepsy, or middle ear or sinus disease excluded the patient. Before treatment all patients had a general medical and aural examination, at which the full blood count, sedimentation rate, blood glucose, urea, and electrolyte concentrations, and chest $x$ ray film were obtained and electrocardiography was performed. Patients were asked to take their usual drugs throughout the trial.

The purpose and execution of the trial were explained to each patient, often with a relative present, and an information sheet was provided for patients to read at home before they gave their written consent at entry. The trial protocol was approved by the ethics committees of the hospitals. 
Difficulties with travelling on a daily basis to central London resulted in 37 patients (29 at St Thomas's Hospital, eight at Whipps Cross) being treated wholly or in part as inpatients during the week.

\section{PROCEDURE}

Patients were randomly allocated to receive hyperbaric oxygen or placebo treatment in monoplace hyperbaric chambers (Ciebe-Gorman, Vickers Lotus or Clinical). In these chambers the patients are compressed within the gas mixture which they breathe and facemasks are not used. Patients in the treatment group received oxygen at 2 atmospheres absolute. The chamber was flushed with oxygen initially and then compressed to 2 atmospheres absolute over 15-20 minutes. Compression was maintained for 90 minutes, and decompression occurred over about 10 minutes. The oxygen concentration in the chamber was regularly monitored for each patient and varied between $94 \%$ and $98 \%$. Samples of gas taken during six different treatment sessions at both centres yielded partial pressures of oxygen varying from 192.9 to $199.5 \mathrm{kPa}$ (1447 to $1496 \mathrm{~mm} \mathrm{Hg}$ ). A similar protocol was followed with the placebo group except that air was used to compress the chamber to $1 \cdot 1$ atmospheres absolute: this was found in preliminary experiments to be virtually indistinguishable subjectively from oxygen at 2 atmospheres absolute. Partial pressures of oxygen on six occasions in the control group varied from 21.3 to $21 \cdot 5 \mathrm{kPa}$ (159 to $161 \mathrm{~mm} \mathrm{Hg}$ ).

Twenty treatment sessions were administered to each patient on successive working days. The patients could not see the gas controls or delivery lines. The use of monoplace chambers limited the number of patients being treated at each hospital to three or four in succession each day, and this reduced the opportunities for patients to compare their experiences. Treatment was supervised throughout by nursing sisters experienced in both hyperbaric treatment and intensive care, and the chambers were sited in general hospitals with full emergency medical and anaesthetic cover.

\section{ASSESSMENTS}

Patients were assessed by a consultant neurologist (CMW or CRAC) and an occupational therapist (Mrs L Jones), who were unaware of the treatment received by the patient. An initial assessment (assessment 1 ) was performed in the week before treatment and assessments 2-6 immediately after and one, three, six, and 12 months after treatment.

\section{Objective tests}

At each assessment all the patients' scores on the Kurtzke disability, functional, and incapacity scales were determined ${ }^{16}{ }^{17}$; also measured were the time taken to walk $50 \mathrm{~m}$ with or without aid, visual acuity (Snellen chart), colour vision (Ishihara plates), macular threshold (Friedmann analyser), muscle strength in elbow flexion and extension and hip flexion, ${ }^{18}$ vibration threshold in both thumbs and great toes (biothesiometer), ${ }^{19}$ and timed tests of hand function. ${ }^{20}$ The environmental status scale was completed on one occasion only. ${ }^{17}$ Tests were performed at a similar time of day, in the same place, and under similar conditions of lighting, temperature, and dress on each occasion and were scored without reference to previous assessments.

\section{Subjective tests}

Each patient kept a urinary diary for a week before each assessment and recorded the number of times they passed urine during the day and the night and, when appropriate, the number of episodes of incontinence. They also recorded subjectively on an analogue scale whether relevant symptoms had improved or worsened; the scale consisted of a $200 \mathrm{~mm}$ line, the centre of which $(0)$ represented their state before treatment and which extended from $+100 \mathrm{~mm}$ ("fully back to normal") to $-100 \mathrm{~mm}$ ("as bad as I could be"). All patients completed a scale of their overall feeling and were also offered scales specifically relating to walking, balance, spasms, vision, bladder and bowel function, fatigue, and sensory disturbance to complete if these were abnormal. The examiner filled in a scale of his overall impression of change.

\section{Other measurements}

Visual (pattern) evoked responses were assessed before and at the end of treatment using standard techniques (Drs P F Prior, P C Sheaff, P Fenwick) in 31 patients given hyperbaric oxygen and 28 given placebo. The latency of the P100 wave was measured when possible for each eye and findings in the two treatment groups compared.

Magnetic resonance imaging was performed at either the National Hospital for Nervous Diseases (Professor W I McDonald, Dr I Ormerod) or St Bartholomew's Hospital (Dr M Charlesworth) before and after treatment in eight patients treated with hyperbaric oxygen and seven treated with placebo.

Micturating cystometrography was performed on nine patients given hyperbaric oxygen and 11 control patients before and immediately after treatment (Mr E H Palfrey, Mr M Bultitude). These patients were selected because of the severity of their urinary symptoms, and all were being treated at St Thomas's Hospital.

Rates of secretion of cortisol were measured before and during treatment in the first 33 patients ( 19 given hyperbaric oxygen, 14 given placebo) using a technique modified from that of Kelly $e t a l^{11}$ (Professor R Brooks, Dr P Marshall Jones).

\section{STATISTICAL METHODS}

Data processing and statistical analysis were carried out in the department of community medicine at St Thomas's Hospital. The null hypothesis was that the differences in scores between assessments 2-6 and assessment 1 (before treatment) would be the same in the treatment and placebo groups with respect to major criteria of outcome-that is, the disability status score, the time taken to walk $50 \mathrm{~m}$, and the subjective overall opinions of both patients and neurologists. For the Kurtzke disability status score (range $0-10$, subdivisions of 0.5 ) it was assumed that $95 \%$ of patients could be assessed within \pm 2.0 points of their "true" score. Thus 84 patients ( 42 in each treatment group) were necessary to detect a 1.0 unit difference between groups in the change in score with a power of $90 \%$ and a false positive risk of $5 \%$.

The differences in the scores for each variable between the two treatment groups were compared using Student's $t$ test. Subjective analogue scores (initially 0 by definition) in the two treatment groups were compared using the mean and standard deviations of the actual scores ( $t$ test) and by scoring each analogue scale according to three categories-namely, worse, better, or unchanged-and using a $\chi^{2}$ test.

\section{Results}

Forty four patients were entered into the trial at St Thomas's Hospital (22 hyperbaric oxygen, 22 placebo) and 40 at Whipps Cross (20 hyperbaric oxygen, 20 placebo). All these patients were assessed before treatment (assessment 1), at the end of the treatment period (assessment 2), and one month after the treatment period (assessment 3 ). This report is of these short term results. Five patients (two receiving hyperbaric oxygen and three receiving air) failed to complete 17 treatments. The reasons for this were claustrophobia or anxiety (two), influenza (one), bleeding from the ear (one), and the diagnosis of cardiac failure after entry into the trial but before any treatment in the chamber (one). These patients were followed up, and the results were analysed on an intention to treat basis. Results from the two hospitals were analysed separately and no differences in major criteria of outcome emerged. The combined results for the two hospitals ( 84 patients) are therefore presented together.

The randomisation procedure resulted in the two groups being similar with respect to sex distribution, age, duration of disease, time since last relapse, time since last steroid or immunosuppressive treatment, and degree of disability as judged by the scores on the disability, incapacity, and environmental status scales (table I); functional system scores were also similar, but at the start of the study the patients in the group treated with hyperbaric oxygen walked $50 \mathrm{~m}$ slightly more quickly than the controls. Most of the patients had disease that was chronically progressive; in some it had been so from the outset, but others had initially had relapses.

\section{MAJOR OUTCOMES (table II)}

Both groups of patients noticed small significant subjective improvements at assessment 2 (at the end of the treatment period), but this subjective change was not significantly different between the two groups at either assessment 2 or 3 (that is, after the patients had returned to their usual lifestyle for a month). The neurologists' overall impression of change did not differ significantly from zero in either treatment group. Mean changes in the score on the disability status scale were small and did not differ between the groups. The time taken to walk $50 \mathrm{~m}$ had not changed significantly by either assessment 2 or 3: at assessment 2 the change in walking time actually favoured the placebo group, the mean time taken to walk $50 \mathrm{~m}$ being $11.9 \mathrm{~s}$ 
TABLE I-Clinical data on entry to study (figures are means (SD))

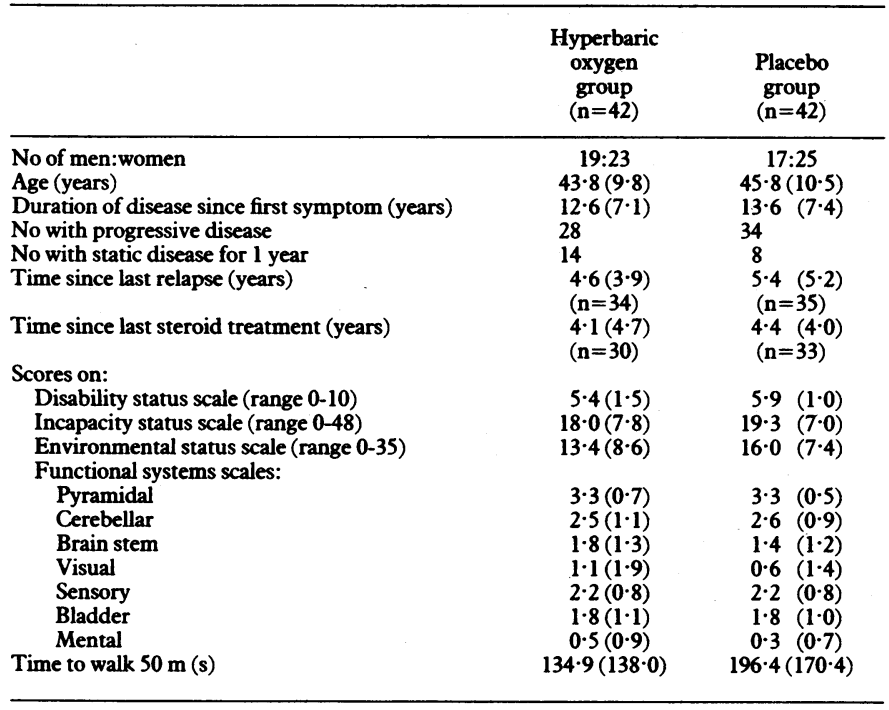

less than the time at assessment 1 compared with $9.0 \mathrm{~s}$ longer in the group given hyperbaric oxygen $(\mathbf{p}<0 \cdot 1)$.

Although the groups did not differ much in age, sex ratio, and disease pattern, minor differences might have had effects sufficient to obscure a small but real difference between the treatment groups. To allow for this the comparisons shown in table II were repeated using multiple regression, which also allowed for differences between the hospitals. There was still no evidence of a systematic difference between the treatment groups. None of these variables had very Gaussian distributions, but comparisons with the Mann-Whitney test, which avoids such assumptions about distribution, showed even less evidence of differences between the groups.

TABLE II-Mean (SD) changes in major criteria of outcome between assessments 2 and 1 and 3 and 1 by treatment group

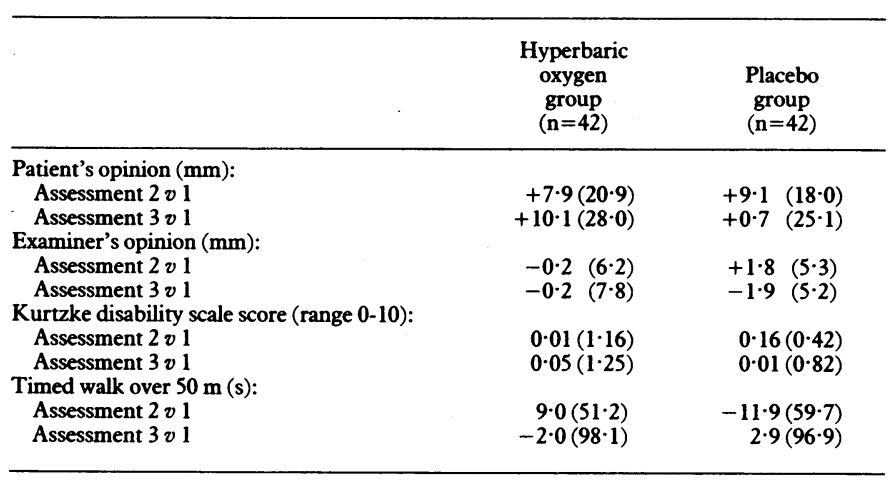

\section{OTHER SUBJECTIVE OUTCOMES}

Virtually all patients scored their impressions of change in walking, balance, vision, fatigue, spasms, and bladder function as better, worse, or unchanged, but no significant differences in the proportions whose symptoms improved were found between the treatment groups (table III). More patients given hyperbaric oxygen noticed a change in balance after treatment $\left(\chi^{2}=5 \cdot 77, p=0.06\right)$, but they were fairly equally divided over whether this was deleterious (13) or beneficial (11). Increased fatigue was unrelated to whether patients received hyperbaric oxygen or air but was associated with outpatient treatment $\left(\chi^{2}=7.06, p=0.006\right)$; thus 18 outpatients and five inpatients felt more fatigue after treatment and 26 outpatients and 31 inpatients felt the same or less fatigue.

\section{OTHER RESULTS}

With respect to the 40 other variables assessed clinically (see appendix) two differences between the treatment groups reached the conventional $5 \%$ level of significance. At assessment 3 the functional system score for sensation had improved by 0.38 (SD 0.76 ) in the group given hyperbaric oxygen compared with no change $(0.00(0.88))$ in the group given placebo $(t=2 \cdot 114, \mathrm{p}=0.038)$. There was no correlation between subjective scores for sensation and the change in the functional system score for sensation. The time taken to write a standard sentence with the left hand was significantly reduced at assessments 2 and 3 in the group given hyperbaric oxygen, but none of the seven other tests of function in the same hand or the eight in the right hand showed a significant change.

TABLE III-Proportions of patients who claimed that symptoms had improved between assessment 1 and assessments 2 and 3 by treatment

\begin{tabular}{lccccc}
\hline & \multicolumn{2}{c}{ Assessment 2} & & \multicolumn{2}{c}{ Assessment 3} \\
\cline { 2 - 3 } \cline { 5 - 6 } \cline { 5 - 6 } Symptom & $\begin{array}{c}\text { Hyperbaric } \\
\text { oxygen } \\
\text { group }\end{array}$ & $\begin{array}{c}\text { Placebo } \\
\text { group }\end{array}$ & & $\begin{array}{c}\text { Hyperbaric } \\
\text { oxygen } \\
\text { group }\end{array}$ & $\begin{array}{c}\text { Placebo } \\
\text { group }\end{array}$ \\
\hline Walking & $11 / 39$ & $16 / 41$ & & $12 / 39$ & $14 / 42$ \\
Balance & $10 / 40$ & $10 / 41$ & & $11 / 38$ & $8 / 41$ \\
Fatigue & $5 / 40$ & $10 / 41$ & & $8 / 39$ & $9 / 42$ \\
Spasms & $8 / 40$ & $5 / 41$ & & $9 / 39$ & $4 / 42$ \\
Bladder & $14 / 40$ & $13 / 41$ & & $13 / 40$ & $12 / 42$ \\
Vision & $2 / 40$ & $3 / 41$ & & $4 / 39$ & $6 / 42$ \\
\hline
\end{tabular}

No differences between treatment groups were found in the latency of the P100 wave of the visual evoked response when this could be measured ( 54 eyes in 32 patients given hyperbaric oxygen compared with 55 eyes in 29 patients given placebo). Magnetic resonance scans (eight patients given hyperbaric oxygen, seven given placebo) were unchanged by treatment. Micturating cystometrograms were obtained in 20 patients (nine given hyperbaric oxygen, 11 given placebo). In the group given hyperbaric oxygen bladder capacity increased in five patients and was unchanged in four; in the group given air it improved in one, was unchanged in nine, and was worse in one $\left(\chi^{2}=5.44, p=0.07\right)$-that is, there was a trend in favour of the group given hyperbaric oxygen that was just short of significance. Scores for subjective assessment of bladder function and urinary diary scores in this group of 20 patients did not correlate with improvement in bladder capacity. Rates of secretion of cortisol were measured in 19 patients given hyperbaric oxygen and 14 patients given air before and during treatment: there was no significant increase in secretion as a result of either treatment and no difference between the groups.

\section{UNWANTED EFFECTS (table IV)}

Both groups of patients experienced unwanted effects from the treatment. Minor ear discomfort was the commonest problem. Two patients required the insertion of grommets in order to continue treatment. One patient, who

TABLE IV-Numbers of patients in each group with side effects

\begin{tabular}{lcc}
\hline & $\begin{array}{c}\text { Hyperbaric } \\
\text { oxygen } \\
\text { group }\end{array}$ & $\begin{array}{c}\text { Placebo } \\
\text { group }\end{array}$ \\
\hline Ear discomfort & $26(3$ severe $)$ & 10 \\
Deafness & 8 & 3 \\
Sinus pain & 2 & 1 \\
Headache & 4 & 4 \\
Leg pain & 5 & 4 \\
Visual disturbance & 8 & 3 \\
Nausea & 3 & 1 \\
Fatigue & 16 & 20 \\
Fear or anxiety & $9(2$ severe $)$ & 5 \\
\hline
\end{tabular}

sneezed during decompression, had bleeding from the external auditory meatus and was presumed to have perforated the tympanic membrane. No patient had longlasting aural side effects. Visual disturbances consisted of blurring of vision, usually towards the end of treatment, which lasted for 30 minutes to six hours after treatment but for several days in one case; one patient remarked on a disturbance of colour vision after treatment with hyperbaric oxygen. Two patients became anxious and claustrophobic and had to withdraw from treatment with hyperbaric oxygen for this reason alone. 


\section{Discussion}

We did not find any systematic benefit from giving hyperbaric oxygen to patients with chronic progressive or static multiple sclerosis. In our view it would be possible for patients to experience appreciable benefits without showing a change in score on the disability state or functional system scale. For instance, the degree of benefit experienced by patients taking antispasticity agents, though regarded as clinically useful, rarely influences ambulation sufficiently per se to result in a change in Kurtzke grade. Patients treated with hyperbaric oxygen, however, were unable to detect appreciable benefits as compared with the group treated with placebo. We had wondered whether improvements might occur in specific variables such as muscle strength, vibration threshold, or bladder function that might hint at underlying improvements in neurological function but be insufficient to be obvious to patient or examiner; improvements in evoked responses or magnetic resonance imaging could also represent relevant findings in response to treatment even if no clinical benefit accrued. We found no significant benefit, however, in any objectively measured variable apart from the functional system scale for sensation and writing time in the left hand. These findings, however, did not correlate with any subjective improvement, lowering of vibration threshold, or improvement of other hand functions, and we strongly suspect that they were due to chance and clinically irrelevant.

We analysed our data to see whether exclusion of patients with static disease gave more favourable results, but it did not.

Although our patients had moderately severe disease, they were all mobile to some degree and, at least when first seen, could walk 50 $\mathrm{m}$. They had disease of similar duration and severity to patients reported on by Fischer et al..$^{7}$ The reports of Neubauer do not provide clear information on the degree of disability in his patients, but 179 out of 250 patients are described as having had symptoms, signs, or disability for more than five years and being "moderately disabled" or "totally incapacitated": of these, 89-91\% "responded" to treatment in an open study. ${ }^{3}$ Considerable evidence of potential patient bias emerged from our study. Most of our patients had great expectations of their treatment even though they appreciated the possibility that they might receive a placebo. Most clearly took the view that if they felt better after treatment they must have received hyperbaric oxygen and that if their condition was unchanged or worse they had received placebo. One patient, whose condition deteriorated dramatically in the month after treatment with hyperbaric oxygen so that she could not walk at all, went to have treatment with hyperbaric oxygen elsewhere because she "knew" that she had received only air: her condition improved rapidly after this second course of treatment.

Our monoplace chambers probably resulted in higher arterial partial pressures of oxygen than were recorded in the trial of Fischer et al, but we were unable to measure them directly for technical reasons. As patients breathed a gas mixture of $95-98 \%$ oxygen at 2 atmospheres absolute and had no major cardiorespiratory disorder, however, the arterial pressure of oxygen was probably similar to that in the study of Barnes et al $^{14}$ although no reports have indicated what pressure of oxygen might be expected close to multiple sclerosis plaques. The trial of Barnes et al was criticised for having used excessive treatment pressures, and claims were made on both theoretical and clinical grounds that partial pressures of oxygen around 1.5 atmospheres absolute were more appropriate. Neubauer's series of patients, however, are described as having been treated in monoplace chambers with four treatments at 1.5 atmospheres absolute followed by 16 at 2 atmospheres absolute for between and 60 and 90 minutes, with follow up treatments at 2 atmospheres absolute. This regimen was said to have produced a dramatic response in $39 \%$ of 250 patients, most of whom had chronic progressive disease, and minimal to moderate improvement in another $52 \%$.

The results from the Newcastle trial ${ }^{14}$ and our own on a total of 204 patients studied under double blind conditions in the United Kingdom fit in with the findings of several smaller studies recently reported in the United States at a meeting of the American Academy of Neurology: in three independently conducted studies of 18 patients (in a crossover study), ${ }^{22} 40$ patients, ${ }^{23}$ and 57 patients, ${ }^{24}$ performed double blind and reported in abstract form, no overall benefit emerged from treatment with hyperbaric oxygen. Findings from a Swedish study of 24 patients were essentially similar. ${ }^{25}$

Our findings, obtained with detailed methods of assessment, together with the findings from other double blind trials have failed to confirm those of Fischer et al. ${ }^{7}$ There appears to be little basis for recommending this treatment to patients with multiple sclerosis.

ADDENDUM - The fourth (three month) and fifth (six month) assessments have been completed in all patients and the sixth (one year) assessment in 45 patients. No significant differences in major or subjective outcomes have emerged between treatment groups.

We thank the following for their support and help: the Multiple Sclerosis Society; Dr R E Kelly; Dr W K Slack, Dr H E R Chew, S Deacon, and staff of the intensive care unit, Whipps Cross Hospital; Dr T Bates, Dr C Foster, and staff of the radiotherapy department, St Thomas's Hospital; J E Saunders, J Evans, and J Burns of the department of medical physics, St Thomas's Hospital; the department of occupational therapy, the National Hospital, Queen Square, London; R Rumun for data handling and programming; and A Tilley and J Jones for secretarial work.

\section{References}

1 Boschetty V, Cernoch J. Aplikace kysliku za pretlaku u nekterych neurologickych anemocneni. Bratisl Lek Listy 1970;53:298-302.

2 Baixe JH. Bilan de onze années d'activité en médecine hyperbare. Medecine Aeronautique et Spatial Medecine Subaquatique et Hyperbare 1978;17:90-2.

3 Neubauer RA. Treatment of multiple sclerosis with monoplace hyperbaric oxygenation. $f$ Fla Med Assoc 1978;65: 101.

4 Neubauer RA. Exposure of multiple sclerosis patients to hyperbaric oxygen at 1.5-2 ATA: a

preliminary report. F Fla Med Assoc 1980;67:498-504.
5 Pallotta R. La terapia iperbarica della sclerosis multipla. Minerva Med 1982;73:2947-54.

\section{Appendix}

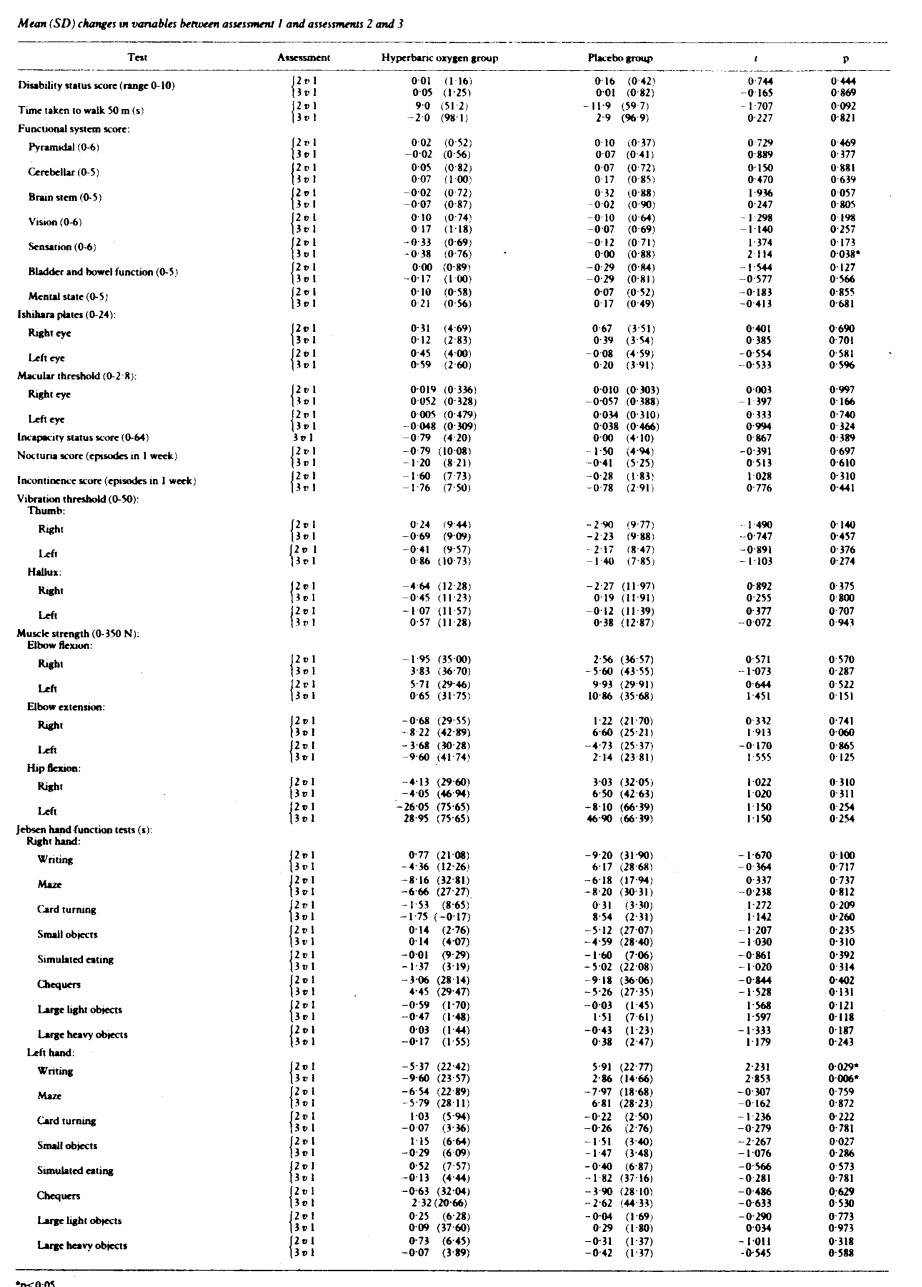


6 Action for Research into Multiple Sclerosis. Hyperbaric oxygen: the Dundee study. London: ARMS Education Services, 1983.

7 Fischer BH, Marks M, Reich T. Hyperbaric oxygen treatment of multiple sclerosis: randomized, placebo controlled double blind study. $N$ Engl I Med 1983;308:181-6.

8 Kelly DL, Lassiter KRL, Vongsvivut A, Smith JM. Effects of hyperbaric oxygenation and tissue oxygen studies in experimental paraplegia. $\mathcal{f}$ Neurosurg 1972;36:425-9.

9 Warren J, Sacksteder MR, Thuning CA. Oxygen immunosuppression: modification of experimental allergic encephalomyelitis in rodents. I I mmunol 1978;121:315-20.

10 Yeo JD, Lowry C, McKenzie B. Preliminary report on ten patients with spinal cord injuries treated with hyperbaric oxygen. Med f Aust 1978;ii:572-3.

treated with hyperbaric oxygen. Med $\mathcal{A}$ Aust $1978 ; \mathrm{ii}: 572-3$.
Jones RF, Unsworth IP, Marosszeky JE. Hyperbaric oxygen and acute spinal cord injuries in humans. Med J Aust 1978;ii:573-5.

12 Holbach KH, Caroli A, Wassmann H. Cerebral energy metabolism in patients with brain lesions at normo- and hyperbaric oxygen pressures. $\mathcal{I}$ Neurol 1977;217:17-30

13 Bass BH. Hyperbaric oxygen for patients with multiple sclerosis. Br Med f 1984;288: 1230.

14 Barnes MP, Bates D, Cartlidge NEF, French JM, Shaw DA. Hyperbaric oxygen and multiple sclerosis: short term results of a placebo-controlled, double blind trial. Lancet 1985;i:297-300.

$15 \mathrm{McDonald}$ WI, Halliday AM. Diagnosis and classification of multiple sclerosis. Br Med Bull 1977;33:4-8.

16 Kurtzke JF. Further notes on disability evaluation in multiple sclerosis with scale modifications. Neurology (Minneapolis) 1965:15:654-61.
17 Kurtzke JF. A proposal for a uniform minimal record of disability in multiple sclerosis. Acta Neurol Scand 1981;64, suppl 87:110-27.

18 Wiles CM, Karni Y. Muscle strength measurements in patients with peripheral neuromuscular disorders. F Neurol, Neurosurg Psychiatry 1983;46:1006-13.

19 Bloom S, Till S, Sönksen P, Smith S. Use of biothesiometer to measure individual vibration thresholds and their variation in 519 non-diabetic subjects. $\mathrm{Br} \mathrm{Med} \mathrm{f} \mathrm{1984;288:1793-5.}$

20 Jebsen RH, Taylor N, Trieschmann RB, Trotter MJ, Howard LA. An objective and standardised test of hand function. Arch Phys Med Rehabil 1969;50:311-9.

21 Kelly WG, Rannucci SR, Shaver JC. A rapid and precise method for the estimation of production rate of cortisol in man. Steroids 1968;11:429-52.

22 Massey EW, Shelton DL, Pact V, et al. Hyperbaric oxygen in multiple sclerosis: double-blind crossover study of 18 patients. Neurology 1985;35, suppl 1:104.

23 Murthy KN, Maurice PB, Wilmeth JB. Double-blind randomised study of hyperbaric oxygen (hbo) versus placebo in multiple sclerosis (ms). Neurology 1985;35, suppl 1:104.

24 Slater GE, Anderson DA, Sherman R, Ettinger MG, Haglin J, Hitchcock C. Hyperbaric oxygen and multiple sclerosis: a double blind controlled study. Neurology 1985;35, suppl 1:315.

25 Neiman J, Nilsson BY, Barr Per O, Perrins DJD. Hyperbaric oxygen in chronic progressive multiple sclerosis: visual evoked potentials and clinical effects. $\mathcal{F}$ Neurol, Neurosurg Psychiatry 1985;48:497-500

(Accepted 21 November 1985)

\title{
Placenta praevia and sex ratio at birth
}

\author{
IAN MACGILLIVRAY， DENNIS DAVEY，SEDICK ISAACS
}

\begin{abstract}
The ratio of male to female sex among infants born to 391 women with and 114079 without placenta praevia was analysed by parity. In the women without placenta praevia the sex ratio decreased significantly with increasing parity, whereas in the women with placenta praevia it increased. Overall, the sex ratio was increased among the women with placenta praevia, particularly multiparas.

An increase in the sex ratio at birth is associated with insemination early or late in the menstrual cycle, which may result in delayed development and implantation of the blastocyst; this may be a predisposing factor in placenta praevia.
\end{abstract}

\section{Introduction}

Several complications of pregnancy, including pre-eclampsia ${ }^{1}$ and premature labour, ${ }^{2}$ are associated with an increase in the ratio of male to female sex at birth. As placenta praevia is believed to be due to delayed development and implantation of the blastocyst, and as abnormalities in the development of the blastocyst are associated with alterations in the sex ratio, we investigated the sex ratio in women with placenta praevia.

\section{Subjects, method, and results}

We determined the sex ratio at delivery in 114470 singleton pregnancies (391 women with and 114079 women without placenta praevia) in the Peninsula Maternity and Neonatal Service region in Cape Town between 1976 and 1983. The women were divided into three groups according to parity (para 1, para 2 and 3, and para 4), those who were para 2 and para 3 being grouped together to ensure adequate numbers in each group (table).

\footnotetext{
Reproductive Medicine Research Unit, Department of Obstetrics and Gynaecology, University of Cape Town, 7925 Cape, South Africa IAN MACGILLIVRAY, FRCOG, professor DENNIS DAVEY, PHD, FRCOG, professor

Department of Medical Informatics, Groote Schuur Hospital, Cape Town, South Africa

SEDICK ISAACS, MSC, FSS, statistician

Correspondence to: Professor Davey.
}

In the reference population without placenta praevia the sex ratio showed a significant decrease with increasing parity $(p<0.02$, Bartholemew's test for proportions qualitatively ordered ${ }^{3}$ ). In women with placenta praevia, however, the sex ratio showed a progressive increase with increasing parity, but this trend was not significantly different from zero owing to the smaller numbers. The proportion of male births by parity in the two groups was compared by ridit analysis. ${ }^{4}$ The mean ridit for the group with placenta praevia was 0.634 (SE 0.022 ), which was significantly greater than the reference ridit value of $0.5(p<0.0001)$ with an odds ratio of $7: 4$ that multiparas with placenta praevia would have a higher proportion of male births than the reference group. Furthermore, in multiparas with four or

Ratio of male to female sex at birth among women with and without placenta praevia

\begin{tabular}{|c|c|c|c|c|c|c|}
\hline \multirow[b]{2}{*}{ Parity } & \multicolumn{3}{|c|}{ Without placenta praevia } & \multicolumn{3}{|c|}{ With placenta praevia } \\
\hline & $\begin{array}{c}\text { No of } \\
\text { male } \\
\text { infants }\end{array}$ & $\begin{array}{l}\text { No of } \\
\text { female } \\
\text { infants }\end{array}$ & $\begin{array}{l}\text { Male:female } \\
\text { ratio }\end{array}$ & $\begin{array}{l}\text { No of } \\
\text { male } \\
\text { infants }\end{array}$ & $\begin{array}{l}\text { No of } \\
\text { female } \\
\text { infants }\end{array}$ & $\begin{array}{l}\text { Male:female } \\
\text { ratio }\end{array}$ \\
\hline 1 & 22601 & 21229 & 1.065 & 34 & 31 & 1.097 \\
\hline 2 and 3 & 24172 & 23027 & 1.050 & 95 & 78 & $1 \cdot 218$ \\
\hline$\geqslant 4$ & 11671 & 11379 & 1.026 & 90 & 63 & 1.429 \\
\hline Total & 58444 & 55635 & 1.050 & 219 & 172 & $1 \cdot 273$ \\
\hline
\end{tabular}

more pregnancies the sex ratio in those with placenta praevia was 1.429 , which was significantly greater than the ratio of 1.026 in the women without placenta praevia $\left(\mathrm{p}<0.043, \mathrm{G}^{2}\right.$ test). ${ }^{5}$ The increase in the sex ratio with increasing birth order among women with placenta praevia compared with those without was thus highly significant.

\section{Discussion}

An increased ratio of male to female sex at birth among women with placenta praevia, particularly multiparas, is a new observation. Moreover, the progressive increase in sex ratio with increasing parity in placenta praevia contrasts with the decrease found in normal pregnancy.

One of the main factors influencing the sex ratio at birth is the time of insemination during the menstrual cycle, more male infants being delivered when insemination occurs two or more days before or after ovulation. ${ }^{6}$ Early and late insemination and alterations in sex ratio are also associated with an increased incidence of miscarriage. ${ }^{7}$ 